\title{
Bundling And Small Business Operations
}

Jess Boronico, New York Institute of Technology, USA James Murdy, New York Institute of Technology, USA

Selene Loughlin, University Of New Haven, USA

\begin{abstract}
The purpose of this paper is to develop and test a model for managing the inventory for a small, student managed food service business. The Hazell Nut Café offers six coffees, six flavors of ice cream, four teas, hot chocolate, assorted pastries, bottled water, vitamin water, and four other types of cold beverages. The purveyors for the all supplies, with the exception of dairy products, have on-call deliveries, but pre-set minimums for order quantities. The dairy company requires a minimum weekly delivery. After nearly one year of operation, the café's student-managers are still developing an inventory management system. The model developed here seeks to provide an easy to understand solution to the supply chain problems encountered by a small business such as the Hazell Nut Café.
\end{abstract}

\section{INTRODUCTION AND LITERATURE REVIEW}

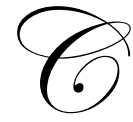

ontemporary businesses face many constraints when developing supply chain management strategies. Economic Order quantity models, just-in time methods, and push and pull procedures all provide managers with well-tested techniques for developing inventory practices that optimize business performance (Ballou, 2000). Given the dynamic nature of supply chains, many organizations seek suppliers that coordinate product delivery dates, volumes and times to better suit the buyer's needs. Vendor managed inventory, which shifts the content and timing of products from the buyer to the provider (Doorling, Scott, and Deakins, 2006), offers yet another approach for addressing the issue of inventory management. If there is adequate purchasing power, these inventory control methods offer a variety of options for efficient management of inputs.

Small businesses, however, are often constrained in the volume of products which they can purchase. Cash flows, storage, and sales may regularly vary, thereby impacting service quality, customer satisfaction, and profitability (Blatherwick, 1996). Food service businesses in particular face the additional challenges of spoilage, customer demands for higher quality products, standardization, narrow profit margins, and regulatory requirements pertaining to the storage, shelf life, and handling of food and beverages. In larger operations, centralized food production facilitates address many of these concerns through best practices well established in the institutional food sector (Rodgers, 2005). Small food service providers are therefore at a competitive disadvantage as they lack many of the prerequisites for developing a competitive supply chain policy.

Food service businesses may also struggle with identifying optimized inventory levels. For example, a product with relatively few ingredients, such as coffee, requires coffee, milk, cream, sugar, artificial sweetener cups, lids, stirrers, coffee filters, and napkins as minimum inputs to deliver the final product. Managers and owners often overstock some of these items because of minimum orders while addressing shortages of others. These problems are typically attributed to errors in order timing and volume. An optimum inventory-consumption model is necessary to reduce unnecessary trips to suppliers or shortages and most advantageous inventory levels, thereby enabling the business to always meet customer demand at any time between vendor deliveries (Farsad and Lebruoto, 1993). Of course, customer demand by day, vendor reliability, quality inventory controls, predicting the sales mix and production controls are also vital to the development of an optimized supply chain.

The purpose of this paper is to develop and test a model for managing the inventory for a small, student managed food service business. The Hazell Nut Café offers six coffees, six flavors of ice cream, four teas, hot chocolate, assorted pastries, bottled water, vitamin water, and four other types of cold beverages. The purveyors for 
the all supplies, with the exception of dairy products, have on-call deliveries, but pre-set minimums for order quantities. The dairy company requires a minimum weekly delivery. After nearly one year of operation, the café's student-managers are still developing an inventory management system. The model developed here seeks to provide an easy to understand solution to the supply chain problems encountered by a small business such as the Hazell Nut Café.

\section{MODEL FORMULATION}

The basic problem to be considered here builds on the foundations of inventory theory (Economic Order Quantity), which gained initial recognition perhaps as early as 1913 (Harris). The interested reader may refer to Erklotter $(1989 ; 1990)$ for a more comprehensive review of EOQ developmental history. The proximate motivation for the extension of the basic model presented here is the existence and interest of niche specific small business owners to understand and develop guidelines concerning replenishment policies for diverse/multiple product lines. In many of these instances, business owners procure inventory personally without a purveyor, especially for small operations such as café stands or kiosk operations. In this way replenishment policies differentiate themselves from those that are suggested through the use of the standard EOQ model, in that (1) ordering costs may be modeled primarily as the opportunity cost of lost labor for the time taken to commute to and from the supplier and purchase the inventory, (2) by way of simultaneous replenishment, ordering costs may be "bundled," thus leading to efficiencies, and (3) optimal bundling quantities purchased will deviate from those obtained by way of the standard EOQ solutions. The research question addressed here involves determining the impact and policy implications for this type of replenishment strategy and developing an understanding of the form of the optimal solution under these assumptions.

For the purpose of this analysis, we adhere to the standard EOQ assumption of deterministic and constant demand, and first compare the optimal policy that would apply if the procurement policy for each product were modeled independently against those that obtain for the suggested "bundled" replenishment policy, that is, one in which each product is replenished at the same time, with common cycle times therefore imposed for each product. It is assumed that holding costs for inventory can be expressed as a percentage of the unit value of each product (e.g. opportunity cost of capital investments in inventory). The results for the former model, considering the optimal EOQ for each product independently, are well established. That is, the optimal solution for the replenishment quantity and associated total annual cost for each product $i$ is given by:

$$
\begin{aligned}
& Q_{i, I}^{*}=\sqrt{2 K_{i} D_{i} k_{i} U_{i}} \forall i=1,2, \ldots, N, \text { and } \\
& \mathrm{TC}_{I}^{*}=\sum_{i=1}^{N} \sqrt{2 K_{i} D_{i} k U_{i}} ; \text { where }
\end{aligned}
$$

$K_{i}=$ the ordering cost that is incurred for each replenishment,

$D=$ the annual demand for product $i$,

$k=$ the holding cost expressed as a percentage of a product unit value; and

$U_{i}=$ the unit value for product $i$, and

$N=$ number of products.

Throughout this analysis the subscript $I$ is use to designate the unbundled, or "independent" model formulation, as opposed to the "bundled" formulation, which will be designated with the subscript $B$. Finally, note that the model (1)-(2) results in a solution for each product with a unique cycle time. In those cases where cycle times might be equal, efficiencies might obtain through the bundling of those products with common cycle times by way of potential decreased ordering costs. Hence (2) represents an upper bound on total cost. The consideration of these efficiencies and bounds does not impact on the result of the comparative analysis below. 
For the bundled replenishment option, the EOQ model may be written as follows:

$\operatorname{MinimizeTC}\left(Q_{i} \mid i=1,2, \ldots, n\right)=\frac{K D_{1}}{Q_{1}}+k \sum_{i=1}^{n} \frac{U_{i} Q_{i}}{2}$

Subject to $\frac{D_{1}}{Q_{1}}=\frac{D_{i}}{Q_{i}} \forall i=2, \ldots, n$

$$
Q_{i} \geq 0 \forall i=1,2, \ldots n
$$

Note that equation (3) considers a bundled ordering cost, since constraint (4) ensures that all products have identical cycle times, with subsequent replenishment of all products occurring at the same time as part of a common bundle. Hence one common order cost $K$ applies to each replenishment cycle. The consideration of multiple products requiring trips to different suppliers with varying order costs is briefly addressed following this initial analysis. Utilizing (4), model (3)-(5) may be rewritten as:

$\operatorname{MinimizeTC}\left(Q_{1}\right)=\frac{K D_{1}}{Q_{1}}+\frac{k}{D_{1}} \sum_{i=1}^{n} \frac{U_{i} D_{i} Q_{1}}{2}$

Where $Q_{1}$ is restricted to non-negative values. The solution for the model (6) is easily derived, and is given by:

$$
Q_{i, B}^{*}=\sqrt{\frac{2 K D_{i}}{\frac{k}{D_{i}} \sum_{i=1}^{N} U_{i} D_{i}}} \forall i=1,2, \ldots, N
$$

With resulting optimal total cost given by:

$$
\mathrm{TC}_{B}^{*}=\sqrt{2 K k \sum_{i=1}^{N} D_{i} U_{i}}
$$

Noting that only positive roots apply concerning the solutions to (1), (2), (7), and (8), it is straightforward to establish the following:

Theorem 1: $T C_{B}^{*} \leq T C_{I}^{*}$

Proof: Results obtain by way of the direct algebraic manipulation of equations (2) and (8). $Q E D$

Implication of Model 1: Theorem 1 establishes that for multiple products, bundling product replenishments together with a common cycle time minimizes overall replenishment costs. This is noteworthy given that the model (6) imposes order quantities that would vary from those that obtain from utilizing the standard EOQ model for each product independently, to the extent that order quantities must be set so as to ensure equal cycle times. Result (7) provides the optimal order quantity for each product per the bundling strategy. As noted earlier, this is especially noteworthy for small business owners who may actually attend to their own inventory replenishment by driving to local warehouses or bulk-discount outlets, where the lost time results in opportunity cost of labor (which may be modeled as a part of the ordering cost). Of course, the standard result obtains, under the assumption of deterministic demand, of replenishing with appropriate lead-time so that inventory arrival coincides with depletion of inventory. The situation of setting safety stock is more complex when stochastic demand is introduced into model 1 , and is left as an extension to the basic model presented here. 


\section{NUMERICAL EXAMPLE}

This section will demonstrate how to apply the mathematical model results obtained in (7) and (8), and also demonstrate how results may be obtained by way of technology ${ }^{1}$. The technology application provides a protocol and suggested methodology that can be utilized as a decision support model for small business operations. The example presented here reflects a proxy operation of a small café based on an actual Small Business operation in the Greater New Haven geographical area.

Two commodities are considered for purposes of this example: Regular and Irish coffee. Ingredients required for these two products are coffee grinds (raw material 1), whiskey (raw material 2), and sugar (raw material 3), which cost $U_{1}=\$ 3.60$ per pound, $U_{2}=\$ 39.99$ per bottle, and $U_{3}=\$ 0.23$ per pound, respectively. One bottle of whiskey holds 1.75 liters, or 59.5 ounces. Coffee is served in 8 ounce cups, and one pound of grinds (mixed with water) is utilized per gallon of coffee (128 ounces), which results in 16 cups per gallon. It is assumed that, on average, a consumer adds .75 tablespoons of sugar per cup. Irish coffee requires 1.5 ounces of whiskey and 1 tablespoon of sugar in addition to 6.5 ounces of regular coffee. It is assumed that demand for Regular and Irish coffee are 500 and 200 cups per day, respectively. This results in a daily unit demand for raw materials of $D_{1}=41.4, D_{2}=5$, and $D_{3}=6$ units of coffee grinds (oz), whisky (oz), and sugar(tsp), respectively. Carrying costs are assumed to be ten $\left(k_{c}=.10\right)$ percent of unit value monthly, representing standard storage, insurance, opportunity cost of capital, and related costs of maintaining inventory. Ordering costs are $\$ 20$ per hour, and reflect the cost of the manager driving to the supplier to procure raw materials. It is assumed that the drive to and from the outlet takes one hour per replenishment. We consider a planning horizon on a monthly basis.

The mathematical solution (7)-(8) results in the following:

Optimal Lot Sizes:

$Q_{1}=242.3 ; Q_{2}=29.3 ; Q_{3}=35.1$

Minimal Total Cost:

$T C^{*}=\$ 205$

Cycle Time $=9.9$ days

The solution to the non-bundled standard EOQ model (1)-(2) results in optimal lot sizes of $Q_{1}=371.5$, $Q_{2}=38.9$, and $Q_{3}=559.0$, with a total cost of $\$ 302$. The cycle times for each of the three raw materials, respectively, are 9, 7.7, and 93 days, respectively. Note that the bundling policy results in a savings of $\$ 97$. This is detailed below, in Table 1:

Table 1: Itemized Inventory Costs - EOQ Traditional versus Bundled ${ }^{2}$

\begin{tabular}{|c|c|c|c|c|c|c|c|c|}
\hline Product & \multicolumn{2}{|c|}{ Optimal Lot Size } & \multicolumn{2}{|c|}{ Carrying Cost } & \multicolumn{2}{|c|}{ Ordering Cost } & \multicolumn{2}{|c|}{ Total Cost } \\
\hline & $\begin{array}{c}\text { EOQ } \\
\text { Traditional }\end{array}$ & Bundled & $\begin{array}{c}\text { EOQ } \\
\text { Traditional }\end{array}$ & Bundled & $\begin{array}{c}\text { EOQ } \\
\text { Traditional }\end{array}$ & Bundled & $\begin{array}{c}\text { EOQ } \\
\text { Traditional }\end{array}$ & Bundled \\
\hline 1 & 371.5 & 242.3 & 66.9 & 43.6 & 66.9 & & 133.8 & \\
\hline 2 & 38.9 & 29.3 & 77.8 & 58.6 & 77.8 & & 155.6 & \\
\hline 3 & 559.0 & 35.1 & 6.4 & .40 & 6.4 & & 12.8 & \\
\hline Total & & & 151.1 & 102.6 & 151.1 & 102.4 & 302.2 & 205 \\
\hline
\end{tabular}

${ }^{1}$ Utilizing either the Microsoft Excel Solver, or a standard Integer Programming software package such as WhatsBest (Lindo Systems Inc.).

2 Note from Table 1 that if the three products were replenished according to the bundled lot sizes, on an individual basis, thus each incurring ordering costs of 102.4, the resulting total costs for the three products 1,2 , and 3 increase by 102.4 , to 169.3 , 180.2 , and 108.8 , with resulting total cost of 458.3 . 
The impact of bundling is apparent immediately. The savings accrued through being able to distribute ordering costs simultaneously across products results in significant savings. These savings accrue by replenishing all products with a common cycle time, and altering the EOQ lot sizes from those that are independently optimal. More importantly, the methodology permits for the specific recommendation concerning how to efficiently implement the bundling policy. That is, specific recommendations concerning the cycle time (9.9 days), and required lot sizes obtain ${ }^{3}$.

As a final extension of the model, we consider an issue of ordering efficiency. Specifically, the model above not only assumes that all products can be replenished simultaneously, but that the ordering cost, represented by the round-trip lost time cost, may be distributed across all products from a common supplier. However, if simultaneous replenishment involved a trip to two or more suppliers, the lost time cost for replenishing $n$ products may exceed the 100 percent efficiency value of $K$, which is the round trip lost time cost (ordering cost) if all products may be obtained at a common supplier. For example, consider Figure 1, where simultaneous replenishment of multiple goods requires stops at both locations $\mathrm{B}$ and $\mathrm{C}$, and one-way travel times are given by $T_{A B} / 2, T_{B C} / 2$ and $T_{A C} / 2$ respectively. It is clear from Figure 1 that for the round trip cycle $A-B-C$ the round trip ordering cost $20\left(T_{A B} / 2+T_{B C} / 2+T_{A C} / 2\right) \geq 20 T_{A C}$, the latter representing the order cost if all products were available at supplier $\mathrm{C}$, with an hourly order cost of $\$ 20$ being applied.

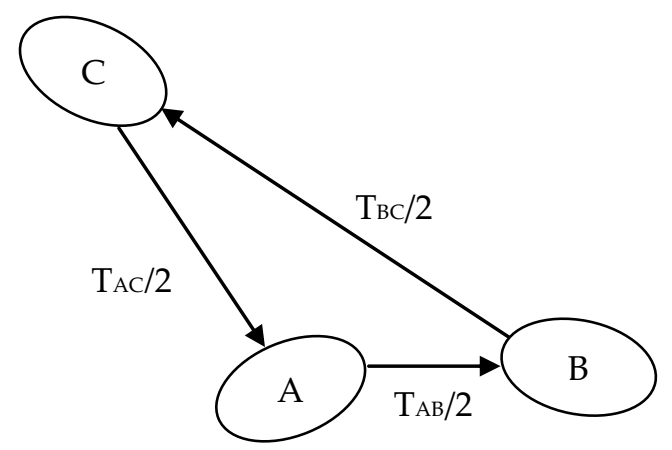

Figure 1: Prototype graphical replenishment scenario

In these instances it is reasonable to develop conditions under which the simultaneous replenishment of all, or a partition of products, continues to result in lower overall costs.

Let $N$ represent the universe of products to be replenished periodically, and let $I \subseteq, N$ represent the set of products in a proposed bundle, which are replenished simultaneously. If $K_{B_{I}}$ represents the bundling ordering (lost time) cost for bundle $I$, it may be established that the set of products $I$ results in a cost savings when utilizing a bundling policy iff:

$K_{B_{I}} \leq \frac{\sum_{i \in I} K_{i} U_{i} D_{i}+\sum_{i \in I} \sum_{j \in I ; j \neq i} \sqrt{K_{i} K_{j} U_{i} U_{j} D_{i} D_{j}}}{\sum_{i \in I} U_{i} D_{i}}$

\footnotetext{
${ }^{3}$ Note that the optimal cycle time of 9.9 days can be approximated in practice by utilizing nine 10 day cycles followed by one 9 day cycle. It is generally recognized, through sensitivity analysis, that incremental modifications in policy of this nature typically have minimal impact on deviations from optimal objective values.
} 
where $K_{i}$ represents the ordering cost (round-trip lost time cost) for raw material $i$. Note that the determination of the raw material cost coefficients $K_{i}$ require consideration of the time components $T$ for each leg of the trip. For example, consider the bundle of three raw materials in the previous numerical example, and assume that coffee grinds and sugar (raw materials 1 and 3) are both available at location $\mathrm{C}$ in Figure 1, but that whiskey (raw material 2 ) must be purchased at location $B$. The home base is located a location A. Further assume that $T_{A B} / 2=.1$ hour and that $T_{A C} / 2=.4$ hour, and that the lost time cost is $\$ 20$ per hour. This results in an ordering cost for coffee grinds of $K_{1}=(.2)(\$ 20)=\$ 4$, and an ordering cost for whiskey of $K_{2}=(.8)(\$ 20)=\$ 16$. The ordering cost for sugar, $K_{3}$, is the same as that for coffee grinds, since it also requires a round trip from location A to location $\mathrm{C}$. The results of Theorem 1 indicate that bundling of coffee grinds and sugar is cost minimizing; hence the question of interest is whether bundling the whiskey together with this package is cost beneficial. Let the round trip travel time between locations $\mathrm{B}$ and $\mathrm{C}$ be given by $T_{B C}=.84$, or equivalently as a one-way travel time of $T_{B C} / 2=.33$ hours. Bundling the three products together is cost minimizing only if:

$$
\begin{aligned}
& K_{B_{123}} \leq \frac{K_{B_{13}}\left(U_{1} D_{1}+U_{3} D_{3}\right)+K_{2} D_{2}+2 \sqrt{K_{B_{13}} K_{2}\left(U_{1} D_{1}+U_{3} D_{3}\right)\left(U_{2} D_{2}\right)}}{U_{1} D_{1}+U_{2} D_{2}+U_{3} D_{3}} \\
& =\frac{(4)(3.60 \cdot 41.4+.23 \cdot 6)+(16)(40)(5)+2 \sqrt{(4)(16)(3.60 \cdot 41.4+.23 \cdot 6)(40 \cdot 5)}}{(3.60)(41.4)+(40)(5)+(.23)(6)}=18.77
\end{aligned}
$$

Note that $K_{B_{123}}=20\left(T_{A B} / 2+T_{B C} / 2+T_{A C} / 2\right)=20(.1+.33+.4)=16.6 \leq 18.77$, therefore bundling all three raw materials together is cost minimizing. Of additional interest is the set portioning problem concerning determining what the appropriate partitions should be that define the raw materials to be bundled together, when there are many raw materials to be replenished. This problem poses significant combinatorial challenges and is left as an implication for future research.

As indicated earlier, the methodology presented here can be reinforced and further supported by way of technology. Figure 2 demonstrates an Excel spreadsheet that incorporates Lindo Systems WhatsBest software scripts to mathematically optimize the replenishment problem presented above. By inspection, the inputs (Mean Demand) are seen to be the demands for final products, which are then atomized into Daily Material requirements. The spreadsheet also considers stochastic demand, hence demand may be simulated by way of software (e.g. Crystal Ball), or inputted to reflect variance across time, such as increased demand during weekends. Initial inventories may be inputted, and the software updates both incoming and ending inventory for each day. The optimization routine determines the cost-minimizing order quantities. Shortage assurance constraints insure that inventories are not depleted. An additional section of the spreadsheet provides the opportunity to input storage requirements, which are programmed as model constraints, if desired. This forms an additional extension to the basic model. One immediately observes that the technological solution for order quantities reflects, quite closely, the theoretical solutions. That is, the technology suggests order quantities for coffee grinds, whiskey, and sugar of 248 (242) pounds, 30.3 (29.3) bottles, and 35.9 (35.1) pounds, respectively (theoretical solutions in parentheses). Minor discrepancies are attributable to start-up conditions and the transient nature of the solution, which has not necessarily achieved steady-state. The output demonstrates the minimal bundling cost of \$201 (\$205), and a comparative cost for the unbundled solution of \$302 (\$302). This type of decision support system can be extended in scope to account for additional precuts and may be implemented by small business owners to assist In the determination of optimal replenishment policies for their raw materials. 
Journal of Business \& Economics Research - January, 2009

Volume 7, Number 1

\begin{tabular}{|c|c|c|c|c|c|c|c|c|c|c|c|c|c|c|c|c|c|c|c|c|c|c|c|c|}
\hline DAY & \multicolumn{2}{|c|}{$\begin{array}{c}\text { MEAN } \\
\text { DEMAND }\end{array}$} & \multicolumn{3}{|c|}{$\begin{array}{c}\text { DAILY } \\
\text { MATERIAL REQ. }\end{array}$} & \multicolumn{3}{|c|}{ INITIAL INV. } & \multicolumn{3}{|c|}{ ENDING INV } & \multicolumn{3}{|c|}{ ORDER QUANT. } & \multirow{3}{*}{\multicolumn{3}{|c|}{$\begin{array}{c}\text { SHORTGE } \\
\text { ASSURANCE }\end{array}$}} & \multicolumn{4}{|c|}{ STORAGE REQ. $\left(\right.$ FT $\left.^{2}\right)$} & \multirow{2}{*}{$\begin{array}{c}\begin{array}{c}\text { STORAGE } \\
\text { CON. }\end{array} \\
\stackrel{0}{\circ}\end{array}$} & \multirow{2}{*}{\multicolumn{2}{|c|}{$\begin{array}{c}\text { ORDER? } \\
\stackrel{8}{8} \\
\stackrel{8}{8}\end{array}$}} \\
\hline & 邆 & 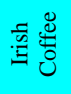 & 这泀 & 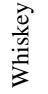 & 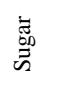 & 冚 & 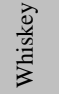 & 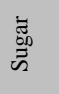 & :ँّ & 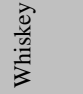 & $\begin{array}{l}\stackrel{\overrightarrow{5}}{\mathrm{~m}} \\
\vec{\omega}\end{array}$ & نัँ & $\begin{array}{l}\frac{\vec{d}}{\frac{\vec{v}}{a}} \\
\frac{\vec{a}}{3}\end{array}$ & 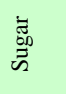 & & & & 苋 & $\frac{\frac{3}{2}}{\frac{2}{2}}$ & $\begin{array}{l}\overline{\tilde{m}} \\
\overrightarrow{\mathrm{m}} \\
\vec{\omega}\end{array}$ & & & & \\
\hline & $\begin{array}{l}\text { Jै } \\
\text { No } \\
0 \\
\infty\end{array}$ & $\begin{array}{l}\text { Ĵ } \\
\text { No } \\
\infty\end{array}$ & 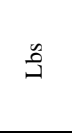 & 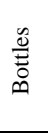 & 胥 & 。 & $\begin{array}{l}\stackrel{0}{0} \\
\frac{\tilde{E}}{0} \\
\infty\end{array}$ & 今ٌ & $\stackrel{0}{0}$ & 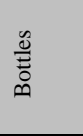 & مُ & $\stackrel{3}{3}$ & 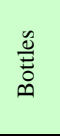 & 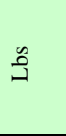 & & & & & 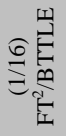 & 空 & 5 & 㝕空 & & $\Sigma$ \\
\hline 1 & 500.0 & 200.0 & 41.4 & 5.0 & 6.0 & 90.0 & 30.0 & 25.0 & 48.6 & 25.0 & 19.0 & 0.0 & 0.0 & 0.0 & $>=$ & $>=$ & $>=$ & 11.3 & 1.9 & 2.8 & 15.9 & & 0 & $=<=$ \\
\hline 2 & 500.0 & 200.0 & 41.4 & 5.0 & 6.0 & 48.6 & 25.0 & 19.0 & 7.2 & 19.9 & 13.0 & \begin{tabular}{ll|}
58.4 \\
\end{tabular} & 0.3 & $\begin{array}{l}10.9 \\
\end{array}$ & $>=$ & $>=$ & $>=$ & 6.1 & 1.6 & 2.1 & 9.7 & & 1 & $<=$ \\
\hline 3 & 500.0 & 200.0 & 41.4 & 5.0 & 6.0 & 165.6 & 20.2 & 24.0 & 124.2 & 15.1 & 18.0 & 0.0 & 0.0 & 0.0 & $>=$ & $>=$ & $>=$ & 20.7 & 1.3 & 2.7 & 24.6 & & 0 & $=<=$ \\
\hline 4 & 500.0 & 200.0 & 41.4 & 5.0 & 6.0 & 124.2 & 15.1 & 18.0 & 82.8 & 10.1 & 12.0 & 0.0 & 0.0 & 0.0 & $>=$ & $>=$ & $>=$ & 15.5 & 0.9 & 2.0 & 18.5 & & 0 & $=<=$ \\
\hline 5 & 500.0 & 200.0 & 41.4 & 5.0 & 6.0 & 82.8 & 10.1 & 12.0 & 41.4 & 5.0 & 6.0 & 0.0 & 0.0 & 0.0 & $>=$ & $>=$ & $>=$ & 10.4 & 0.6 & 1.3 & 12.3 & & 0 & $=<=$ \\
\hline 6 & 500.0 & 200.0 & 41.4 & 5.0 & 6.0 & 41.4 & 5.0 & 6.0 & 0.0 & 0.0 & 0.0 & 248.4 & 30.3 & 35.9 & $\Rightarrow>=$ & $\Rightarrow>=$ & $\Rightarrow>=$ & 5.2 & 0.3 & 0.7 & 6.2 & & 1 & $<=$ \\
\hline 7 & 500.0 & 200.0 & 41.4 & 5.0 & 6.0 & 248.4 & 30.3 & 35.9 & 207.0 & 25.2 & 29.9 & 0.0 & 0.0 & 0.0 & $>=$ & $>=$ & $>=$ & 31.1 & 1.9 & 4.0 & 36.9 & & 0 & $=<=$ \\
\hline 8 & 500.0 & 200.0 & 41.4 & 5.0 & 6.0 & 207.0 & 25.2 & 29.9 & 165.6 & 20.2 & 24.0 & 0.0 & 0.0 & 0.0 & $>=$ & $>=$ & $>=$ & 25.9 & 1.6 & 3.3 & 30.8 & & 0 & $=<=$ \\
\hline 9 & 500.0 & 200.0 & 41.4 & 5.0 & 6.0 & 165.6 & 20.2 & 24.0 & 124.2 & 15.1 & 18.0 & 0.0 & 0.0 & 0.0 & $>=$ & $>=$ & $>=$ & 20.7 & 1.3 & 2.7 & 24.6 & & 0 & $=<=$ \\
\hline 10 & 500.0 & 200.0 & 41.4 & 5.0 & 6.0 & 124.2 & 15.1 & 18.0 & 82.8 & 10.1 & 12.0 & 0.0 & 0.0 & 0.0 & $>=$ & $>=$ & $>=$ & 15.5 & 0.9 & 2.0 & 18.5 & & 0 & $=<=$ \\
\hline 11 & 500.0 & 200.0 & 41.4 & 5.0 & 6.0 & 82.8 & 10.1 & 12.0 & 41.4 & 5.0 & 6.0 & 0.0 & 0.0 & 0.0 & $>=$ & $>=$ & $>=$ & 10.4 & 0.6 & 1.3 & 12.3 & & 0 & $=<=$ \\
\hline 12 & 500.0 & 200.0 & 41.4 & 5.0 & 6.0 & 41.4 & 5.0 & 6.0 & 0.0 & 0.0 & 0.0 & 248.4 & 30.3 & 35.9 & $\Rightarrow>=$ & $\Rightarrow>=$ & $\Rightarrow>=$ & 5.2 & 0.3 & 0.7 & 6.2 & & 1 & $<=$ \\
\hline 13 & 500.0 & 200.0 & 41.4 & 5.0 & 6.0 & 248.4 & 30.3 & 35.9 & 207.0 & 25.2 & 29.9 & 0.0 & 0.0 & 0.0 & $>=$ & $>=$ & $>=$ & 31.1 & 1.9 & 4.0 & 36.9 & & 0 & $=<=$ \\
\hline 14 & 500.0 & 200.0 & 41.4 & 5.0 & 6.0 & 207.0 & 25.2 & 29.9 & 165.6 & 20.2 & 24.0 & 0.0 & 0.0 & 0.0 & $>=$ & $>=$ & $>=$ & 25.9 & 1.6 & 3.3 & 30.8 & & 0 & $=<=$ \\
\hline 15 & 500.0 & 200.0 & 41.4 & 5.0 & 6.0 & 165.6 & 20.2 & 24.0 & 124.2 & 15.1 & 18.0 & 0.0 & 0.0 & 0.0 & $>=$ & $>=$ & $>=$ & 20.7 & 1.3 & 2.7 & 24.6 & & 0 & $=<=$ \\
\hline 16 & 500.0 & 200.0 & 41.4 & 5.0 & 6.0 & 124.2 & 15.1 & 18.0 & 82.8 & 10.1 & 12.0 & 0.0 & 0.0 & 0.0 & $>=$ & $>=$ & $>=$ & 15.5 & 0.9 & 2.0 & 18.5 & & 0 & $=<=$ \\
\hline 17 & 500.0 & 200.0 & 41.4 & 5.0 & 6.0 & 82.8 & 10.1 & 12.0 & 41.4 & 5.0 & 6.0 & 0.0 & 0.0 & 0.0 & $>=$ & $>=$ & $>=$ & 10.4 & 0.6 & 1.3 & 12.3 & & 0 & $=<=$ \\
\hline 18 & 500.0 & 200.0 & 41.4 & 5.0 & 6.0 & 41.4 & 5.0 & 6.0 & 0.0 & 0.0 & 0.0 & 248.4 & 30.3 & 35.9 & $\Rightarrow>=$ & $\Rightarrow>=$ & $\Rightarrow>=$ & 5.2 & 0.3 & 0.7 & 6.2 & & 1 & $<=$ \\
\hline 19 & 500.0 & 200.0 & 41.4 & 5.0 & 6.0 & 248.4 & 30.3 & 35.9 & 207.0 & 25.2 & 29.9 & 0.0 & 0.0 & 0.0 & $>=$ & $>=$ & $>=$ & 31.1 & 1.9 & 4.0 & 36.9 & & 0 & $=<=$ \\
\hline 20 & 500.0 & 200.0 & 41.4 & 5.0 & 6.0 & 207.0 & 25.2 & 29.9 & 165.6 & 20.2 & 24.0 & 0.0 & 0.0 & 0.0 & $>=$ & $>=$ & $>=$ & 25.9 & 1.6 & 3.3 & 30.8 & & 0 & $=<=$ \\
\hline 21 & 500.0 & 200.0 & 41.4 & 5.0 & 6.0 & 165.6 & 20.2 & 24.0 & 124.2 & 15.1 & 18.0 & 0.0 & 0.0 & 0.0 & $>=$ & $>=$ & $>=$ & 20.7 & 1.3 & 2.7 & 24.6 & & 0 & $=<=$ \\
\hline 22 & 500.0 & 200.0 & 41.4 & 5.0 & 6.0 & 124.2 & 15.1 & 18.0 & 82.8 & 10.1 & 12.0 & 0.0 & 0.0 & 0.0 & $>=$ & $>=$ & $>=$ & 15.5 & 0.9 & 2.0 & 18.5 & & 0 & $=<=$ \\
\hline 23 & 500.0 & 200.0 & 41.4 & 5.0 & 6.0 & 82.8 & 10.1 & 12.0 & 41.4 & 5.0 & 6.0 & 0.0 & 0.0 & 0.0 & $>=$ & $>=$ & $>=$ & 10.4 & 0.6 & 1.3 & 12.3 & & 0 & $=<=$ \\
\hline 24 & 500.0 & 200.0 & 41.4 & 5.0 & 6.0 & 41.4 & 5.0 & 6.0 & 0.0 & 0.0 & 0.0 & 248.4 & 30.3 & 35.9 & $\Rightarrow=$ & $\Rightarrow>=$ & $\Rightarrow>=$ & 5.2 & 0.3 & 0.7 & 6.2 & & 1 & $<=$ \\
\hline 25 & 500.0 & 200.0 & 41.4 & 5.0 & 6.0 & 248.4 & 30.3 & 35.9 & 207.0 & 25.2 & 29.9 & 0.0 & 0.0 & 0.0 & $>=$ & $>=$ & $>=$ & 31.1 & 1.9 & 4.0 & 36.9 & & 0 & $=<=$ \\
\hline 26 & 500.0 & 200.0 & 41.4 & 5.0 & 6.0 & 207.0 & 25.2 & 29.9 & 165.6 & 20.2 & 24.0 & 0.0 & 0.0 & 0.0 & $>=$ & $>=$ & $>=$ & 25.9 & 1.6 & 3.3 & 30.8 & & 0 & $=<=$ \\
\hline 27 & 500.0 & 200.0 & 41.4 & 5.0 & 6.0 & 165.6 & 20.2 & 24.0 & 124.2 & 15.1 & 18.0 & 0.0 & 0.0 & 0.0 & $>=$ & $>=$ & $>=$ & 20.7 & 1.3 & 2.7 & 24.6 & & 0 & $=<=$ \\
\hline 28 & 500.0 & 200.0 & 41.4 & 5.0 & 6.0 & 124.2 & 15.1 & 18.0 & 82.8 & 10.1 & 12.0 & 0.0 & 0.0 & 0.0 & $>=$ & $>=$ & $>=$ & 15.5 & 0.9 & 2.0 & 18.5 & & 0 & $=<=$ \\
\hline 29 & 500.0 & 200.0 & 41.4 & 5.0 & 6.0 & 82.8 & 10.1 & 12.0 & 41.4 & 5.0 & 6.0 & 0.0 & 0.0 & 0.0 & $>=$ & $>=$ & $>=$ & 10.4 & 0.6 & 1.3 & 12.3 & & 0 & $=<=$ \\
\hline 30 & 500.0 & 200.0 & 41.4 & 5.0 & 6.0 & 41.4 & 5.0 & 6.0 & 0.0 & 0.0 & 0.0 & 0.0 & 0.0 & 0.0 & $\Rightarrow>=$ & $\Rightarrow>=$ & $\Rightarrow>=$ & 5.2 & 0.6 & 0.7 & 6.5 & & 0 & $=<=$ \\
\hline
\end{tabular}

INPUTS

SOLUTIONS

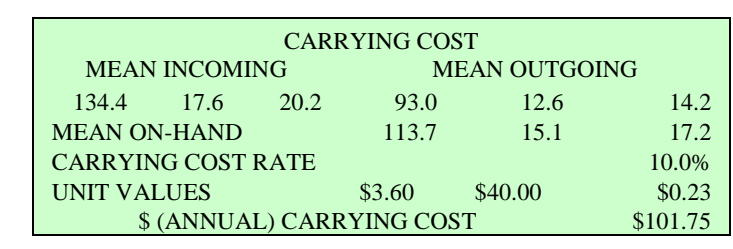

\begin{tabular}{|cccc|}
\hline & & & \\
\hline EOQ OPTIMUM & Q & TOTAL COST & $\mathrm{FT}^{2}$ \\
PRODUCT 1 & 371.5 & 133.7 & 46.4 \\
PRODUCT 2 & 38.9 & 155.6 & 2.4 \\
PRODUCT 3 & 559.0 & 12.9 & 62.1 \\
\hline & & 302.2 & 111.0 \\
\hline
\end{tabular}

Figure 2: Technology Application Demonstration

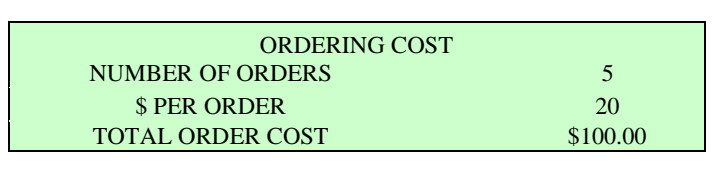

\begin{tabular}{|cc|}
\hline TOTAL COST (BI-ANNUAL) & \\
\$(BI-ANNUAL) HOLDING COST & $\$ 102$ \\
\$(BI-ANNUAL) ORDERING COST & $\$ 100$ \\
\$(BI-ANNUAL) TOTAL COST & $\mathbf{2 0 1 . 7 4 9 7}$ \\
\hline & \\
\hline
\end{tabular}




\section{CONCLUSIONS AND MANAGERIAL IMPLICATION}

The model developed in this paper offers a strategy for inventory management in a small food service operation. The results indicate that optimal levels of inventory for products needing multiple inputs to deliver the final product. The model is particularly appropriate for the Hazell Nut Café given the small amount of storage space available to it and the variety of ingredients necessary to ensure that customer demand is met. Furthermore, the tools needed to ensure that the student managers can continually update the model are familiar to them.

\section{REFERENCES}

1. Ballou, R. (2000), "Evaluating inventory management performance using a turnover curve”, No.1, pp.7285 .

2. $\quad$ Blatherwick, A. (1996), “The supply chain balancing act - stock and service at a profit", Logistics Information Management, No.6, pp.24-26.

3. Erlenkotter, D. (1989), "An early classic misplaced: Ford W. Harris's Economic Order Quantity Model of 1913", Management Science, No.35, pp.898-900.

4. $\quad$ Erlenkotter, D. (1990), "Ford Whitman Harris and the Economic Order Quantity Model", Management Science, No.38, pp.937-46.

5. Farsad, B., \& LeBruto, S. (1993), “A measured approach to food-inventory management”, Cornell Hotel \& Restaurant Administration Quarterly, June 1, pp.

6. Harris, F.W. (1913), "How many parts to make at once", Factory: The Magazine of Management, No.10, pp.135-6.

7. $\quad$ Rodgers, S. (2005), “Selecting a food service system: A review”, International Journal of Contemporary Hospitality Management, No.2, pp.147-156.

\section{NOTES}

